\title{
Observation of Pit Initiation and Growth of Stainless Steel under a Chloride Solution Droplet —Effect of S Content on Pit Initiation, Growth, and Repassivation-*1
}

\author{
Azusa Ooi*2, Yaoki Ise*3, Eiji Tada and Atsushi Nishikata \\ Department of Materials Science and Engineering, School of Materials and Chemical Technology, Tokyo Institute of Technology, \\ Tokyo 152-8552, Japan
}

A system was developed based on which the pit growth automatically stops any time after the pit initiation under a chloride solution droplet. The atmospheric pitting corrosion of austenitic stainless steels with various sulfur (S) concentrations was investigated using this system. The results confirm that the initiation sites of pitting corrosion are manganese sulfide inclusions under the droplets regardless of the $\mathrm{S}$ concentration. In addition, the growth behavior of the active dissolution area is independent of the S concentration. When these specimens are subjected to wet-dry cycle tests, the probability of pitting corrosion increases with increasing $\mathrm{S}$ concentration due to the increase in initiation sites. The onset of pitting corrosion is independent of the chloride concentration. On the other hand, repassivation strongly depends on the $\mathrm{S}$ concentration. [doi:10.2320/matertrans.C-M2020869]

(Received May 11, 2020; Accepted December 9, 2020; Published January 29, 2021)

Keywords: atmospheric corrosion, austenitic stainless steel, pitting, repassivation, manganese sulfide inclusion

\section{Introduction}

Stainless steel (SS) exhibits an excellent corrosion resistance due to the formation of a passive film on its surface. Therefore, SS is widely used in various fields such as architecture and railroad coaches. However, pitting corrosion is a significant problem in marine atmospheric environments because pits might cause strength and design deterioration. In this environment, airborne salts are deposited on the SS surface. Subsequently, water droplets containing chloride ions $\left(\mathrm{Cl}^{-}\right)$form on the surface when the relative humidity $(\mathrm{RH})$ rises above deliquescence humidity at night. In contrast, the concentration of $\mathrm{Cl}^{-}$in the droplet gradually increases with decreasing $\mathrm{RH}$ in the daytime. These $\mathrm{Cl}^{-}$droplets induce the initiation of pitting corrosion. ${ }^{1-4)}$ Temperature, $\mathrm{RH}$, rainfall, and airborne salts are therefore critical environmental factors for the initiation of pitting corrosion of SS in marine atmospheric environments.

Many studies have been conducted to clarify the pitting corrosion mechanism of SS; however, the SS was anodically polarized in an aqueous chloride solution in most of these studies. It is well known that manganese sulfide $(\mathrm{MnS})$ inclusions are the initiation sites for pitting corrosion in $\mathrm{SS}{ }^{5}{ }^{5}$ thus, many researchers have paid attention to $\mathrm{MnS}$ inclusions. Suter and Webb et al. ${ }^{6-11)}$ performed anodic polarization tests on $\mathrm{SS}$ containing $\mathrm{MnS}$ inclusions using a microcapillary cell $(20-1000 \mu \mathrm{m})$. They reported that the $\mathrm{MnS}$ inclusions become the initiation sites of pitting corrosion because of electrochemical dissolution in the passive region of the SS. In recent years, Chiba et al. ${ }^{12-14)}$ developed a unique microelectrochemical measurement system for in situ high-resolution optical microscope observations to directly observe the initiation sites of pitting corrosion. They applied this system to SS304 under anodic

\footnotetext{
${ }^{* 1}$ This Paper was Originally Published in Japanese in Zairyo-to-Kankyo 68 (2019) 347-354.

${ }^{* 2}$ Corresponding author, E-mail: ohi.a.aa@m.titech.ac.jp

${ }^{* 3}$ Graduate Student, Tokyo Institute of Technology. Present Address: Product Analysis Center, Panasonic Corporation, Kadoma 571-8686, Japan
}

polarization in a sodium chloride solution and reported that the initiation sites of pitting corrosion are at the boundaries between the MnS inclusions and SS matrix. Furthermore, it has been suggested that the dissolution of boundaries is due to the synergistic effect of elemental sulfur $(\mathrm{S})$, generated by electrochemical dissolution of $\mathrm{MnS}$ inclusions, and $\mathrm{Cl}^{-}$in the solution and a detailed mechanism of pitting corrosion has been proposed. ${ }^{13)}$

As mentioned above, many studies on pitting corrosion of SS are often performed in aqueous solution under anodic polarization. However, the pit initiation and growth mechanism in aqueous solution might differ from those associated with an extremely thin droplet $(10$ to $100 \mu \mathrm{m})$ in an atmospheric environment. In addition, the pit growth mechanism during pitting corrosion based on anodic polarization in an aqueous solution might differ from that of spontaneous corrosion in an atmospheric environment. A pit is initiated when SS is anodically polarized to the pitting potential $\left(E_{\text {pit }}\right)$ and the pit growth is maintained at $E_{\text {pit }}$ or above $E_{\text {pit }}$ in the former case. On the other hand, spontaneous pit initiation occurs on the SS surface when the open circuit potential (OCP) increases to $E_{\text {pit }}$ or $E_{\text {pit }}$ decreases to OCP due to changes in the droplet thickness and/or $\mathrm{Cl}^{-}$concentration. Immediately after pit initiation, the SS potential shifts into the negative direction (from the passive region to the active dissolution region) and pit growth continues in the active dissolution region. Therefore, we propose a new pitting corrosion test method, which is based on concentrating $\mathrm{Cl}^{-}$ in the droplet by lowering the $\mathrm{RH}$ while maintaining the equilibrium at the air/droplet interface rather than on anodic polarization. ${ }^{1-4)}$ This method seems to be much more representative of the actual marine atmospheric environment.

Regarding the electrochemical measurement for the analysis of the corrosion behavior of metal under the droplet, Stratmann et al. ${ }^{15-17)}$ developed a surface potential measurement method using a Kelvin probe (KP) to avoid contact between the reference electrode (RE) and droplet. They obtained the polarization curves of steel under the droplet. Frankel et al. ${ }^{18)}$ measured the anodic polarization curves of SS304L using KP and showed that $E_{\text {pit }}$ does not change 
regardless of the droplet thickness. On the other hand, our group successfully measured the corrosion rate of iron $(\mathrm{Fe})$ and zinc $(\mathrm{Zn})$ for various droplet thicknesses using electrochemical impedance spectroscopy (EIS); the results showed that the corrosion rates of $\mathrm{Fe}$ and $\mathrm{Zn}$ depend on the droplet thickness. ${ }^{19,20)}$ Furthermore, in addition to general corrosion metal (Fe and $\mathrm{Zn}$ ), EIS was applied to localized corrosion metal (SS), which was exposed to a marine atmospheric environment, the pit initiation was monitored. ${ }^{21)}$ The surface condition and corrosion rate of SS were continuously measured using impedance at $10 \mathrm{kHz}$ and $10 \mathrm{mHz}$, respectively. Tsutsumi et al. prepared an electrode assembly embedded in epoxy resin, which consisted of eight SS plates, a silver (Ag) plate, and two Inconel plates. ${ }^{1,2)}$ The $\mathrm{Ag}$ and Inconel were used as RE and for the calculation of the droplet thickness, respectively. Pit initiation was successfully monitored with increasing $\mathrm{Cl}^{-}$concentration during the drying process of the droplet using the potential change of the Ag plate. Based on this method, the pitting corrosion that occurred in many samples could be simultaneously analyzed. This method is extremely useful for the evaluation of the probability of pitting corrosion because pitting corrosion is a stochastic phenomenon. However, because the SS plates are embedded in resin, the samples occasionally suffered from crevice corrosion. Therefore, we improved this method to avoid crevice corrosions in the recent works. ${ }^{3,4)}$

In this study, we further improved the conventional evaluation system for pitting corrosion in an atmospheric environment. The conventional system was combined with a new system that can automatically stop the pit growth at any time during the pit growth stage. This system was applied to SS304 samples with different S concentrations. The effect of the $\mathrm{S}$ concentration on the pit initiation, pit growth, and repassivation behavior of $\mathrm{SS} 304$ is discussed in detail.

\section{Experimental Procedures}

\subsection{Pit growth automatic stop test}

Austenitic SS304 plates with different concentrations of $\mathrm{S}(10,60,480,1620$, and $3230 \mathrm{ppm})$ were used as samples in this study. Their chemical compositions are shown in Table 1. They are denoted as 10S, 60S, 480S, 1620S, and $3230 \mathrm{~S}$ steel, respectively. Figures 1(a)-(e) show optical
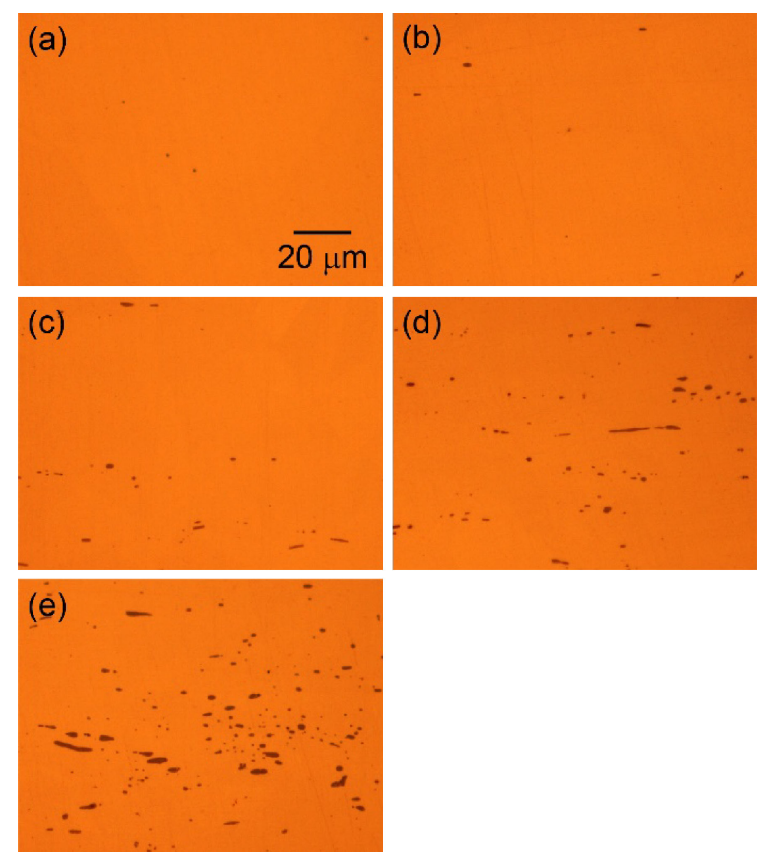

Fig. 1 Optical microscope images of austenitic stainless steel with different sulfur concentrations: (a) 10S, (b) $60 \mathrm{~S}$, (c) $480 \mathrm{~S}$, (d) $1620 \mathrm{~S}$, and (e) $3230 \mathrm{~S}$ steel.

microscope images of the surface of each sample. The black contrast in the images correspond to $\mathrm{MnS}$ inclusions. The number and average size of the inclusions increase with increasing $\mathrm{S}$ concentration.

These samples were cut into $15 \times 10 \times 5 \mathrm{~mm}$ pieces. The surfaces were polished, first with $\mathrm{SiC}$ paper (\#2000) and then with diamond paste $(0.25 \mu \mathrm{m})$. Subsequently, they were ultrasonically cleaned in ethanol and Milli-Q $(18.2 \mathrm{M} \Omega \mathrm{cm})$ for $10 \mathrm{~min}$, respectively, and used as working electrodes (WEs). The WE fixed to the sample holder shown in Fig. 2 and a $1 \mathrm{M} \mathrm{MgCl}_{2}\left(\left[\mathrm{Cl}^{-}\right]=2 \mathrm{M}\right)$ droplet with an initial volume $\left(V_{0}\right)$ of $3 \mu \mathrm{L}$ and diameter $(d)$ of $3 \mathrm{~mm}$ (height $(h) \sim 0.8 \mathrm{~mm}$ ) was placed on the surface. An Ag wire $(\varphi=100 \mu \mathrm{m})$, which was placed directly above the WE, was used as RE. This setup was installed in a programmable constant humidity and temperature chamber (IW222, Yamato Scientific Co., Ltd.). Both edges of the WE were covered with $100 \mu \mathrm{m}$ thick insulating tape and both ends of the Ag

Table 1 Chemical compositions (mass \%) of austenitic stainless steel samples with different sulfur concentrations.

\begin{tabular}{ccccccccccc}
\hline Elements & $\mathrm{C}$ & $\mathrm{Si}$ & $\mathrm{Mn}$ & $\mathrm{P}$ & $\mathrm{S}$ & $\mathrm{Ni}$ & $\mathrm{Cr}$ & $\mathrm{Al}$ & $\mathrm{Fe}$ \\
\hline $10 \mathrm{~S}$ & 0.05 & 0.50 & 1.47 & 0.025 & 0.001 & 8.99 & 18.45 & 0.05 & Bal. \\
& & & & & & & & & \\
$60 \mathrm{~S}$ & 0.05 & 0.50 & 1.47 & 0.023 & 0.006 & 9.00 & 18.19 & 0.02 & Bal. \\
& & & & & & & & & \\
$480 \mathrm{~S}$ & 0.06 & 0.50 & 1.46 & 0.023 & 0.048 & 9.01 & 18.32 & 0.03 & Bal. \\
$1620 \mathrm{~S}$ & 0.05 & 0.49 & 1.41 & 0.023 & 0.162 & 9.04 & 18.36 & 0.04 & Bal. \\
& & & & & & & & & \\
$3230 \mathrm{~S}$ & 0.05 & 0.46 & 1.38 & 0.024 & 0.323 & 9.06 & 18.24 & 0.04 & Bal.
\end{tabular}




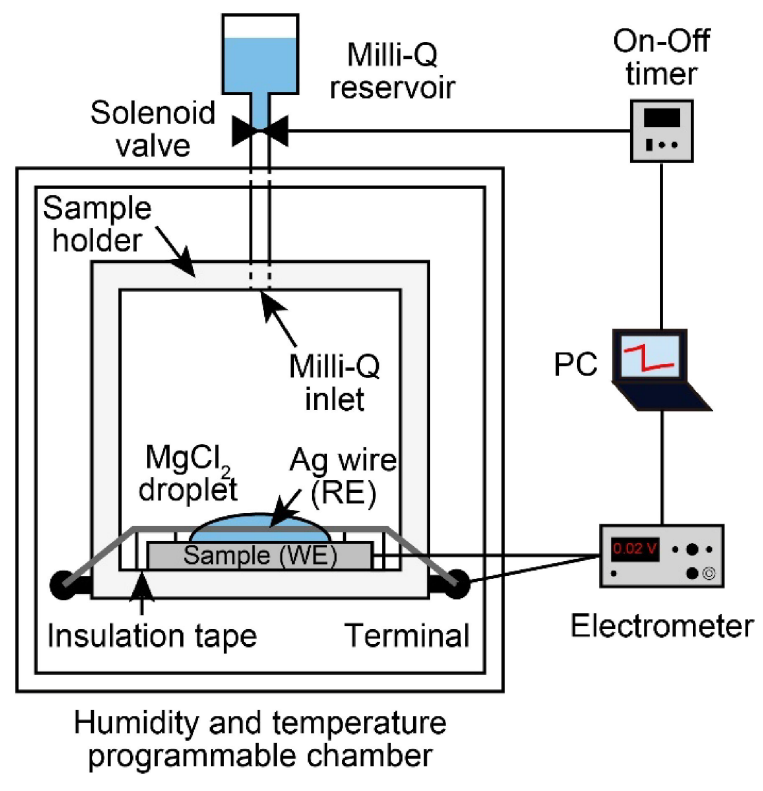

Fig. 2 Schematic drawing of the experimental setup used in this study.

wire were tightly pulled and fixed to the terminals to maintain a constant gap between the WE and RE $(100 \mu \mathrm{m})$. A reservoir containing Milli-Q was directly set above the sample holder. By opening the solenoid valve under the PC control, Milli-Q was automatically released on the WE surface. In this experiment, the temperature was maintained at $298 \mathrm{~K}$. The $\mathrm{RH}$ was maintained at $95 \%$ for the initial $30 \mathrm{~min}$ and was then reduced to $35 \%$ at a constant rate of $5 \% \mathrm{~h}^{-1}$. The $\left[\mathrm{Cl}^{-}\right]$of the droplet is equal to $\sim 2 \mathrm{M}$ at $95 \% \mathrm{RH}^{1)}$ The concentration is almost equal to the initial concentration of the droplet $\left(1 \mathrm{M} \mathrm{MgCl}_{2}\right)$; hence, the droplet does not dry in the first $30 \mathrm{~min}$. This initial period was employed because the initial surface state (passive film state) of the WE immediately after polishing and cleaning might differ in every experiment; thus, the deviation of the surface state could be minimized by applying this initial period. During the drying process, the potential difference between the WE and $\mathrm{RE}\left(E_{\mathrm{SS}-\mathrm{Ag}}\right)$ was measured at an interval of $1 \mathrm{~s}$ using an electrometer (HE-104A, HOKUTO DENKO CORP.). The $E_{\mathrm{SS}-\mathrm{Ag}}$ is given by the following equation:

$$
E_{\mathrm{SS}-\mathrm{Ag}}=E_{\mathrm{corr}(\mathrm{WE})}-E_{\mathrm{Ag} / \mathrm{AgCl}},
$$

where $E_{\mathrm{corr}(\mathrm{WE})}$ is the corrosion potential of the WE and $E_{\mathrm{Ag} / \mathrm{AgCl}}$ is the equilibrium potential of $\mathrm{Ag} / \mathrm{AgCl}$ determined by the following equilibrium reaction:

$$
\mathrm{AgCl}+\mathrm{e}^{-} \rightarrow \mathrm{Ag}+\mathrm{Cl}^{-} .
$$

This means that the potentials of both the WE and RE change during the drying process. However, we previously reported that the change of $E_{\mathrm{corr}(\mathrm{WE})}$ due to the pit initiation and growth is more significant than that of $E_{\mathrm{Ag} / \mathrm{AgCl}}{ }^{3)}$ Thus, the pit initiation and growth can be determined by continuously monitoring $E_{\mathrm{SS}-\mathrm{Ag}}$. In this study, the pit initiation was defined as the change in the potential of $E_{\mathrm{SS}-\mathrm{Ag}}$ by $-0.01 \mathrm{~V} \mathrm{~s}^{-1}$. The solenoid valve was automatically opened $1-1000 \mathrm{~s}$ after the potential change was detected and Milli-Q was released onto the WE surface to stop the pit growth. The initiated pit was observed with a scanning electron microscope (SEM,
JSM-6010LA, JEOL Ltd.) and the inclusions in the pit were analyzed by energy dispersive X-ray analysis (EDX).

\subsection{Wet-dry cycle test}

The same samples that were used in Section 2.1 were cut into $35 \times 25 \times 5 \mathrm{~mm}$ pieces and their surfaces were polished with SiC paper (\#1000). The samples were then ultrasonically cleaned in ethanol and Milli-Q for $10 \mathrm{~min}$. Subsequently, three $1 \mathrm{M} \mathrm{MgCl}_{2}$ droplets with a $V_{0}$ of $50 \mu \mathrm{L}$ and $d$ of $8 \mathrm{~mm}(h \sim 1.9 \mathrm{~mm})$ were formed on the WE surface at even intervals using a micropipette. For each droplet, Ag wires were used as RE. Insulating tape was used to position them to maintain the distance between the WE and RE at $100 \mu \mathrm{m}$. Similar to Section 2.1, the setup was installed in a programmable constant humidity and temperature chamber. The detailed experimental procedure has been previously reported. ${ }^{3)}$ To evaluate stochastic phenomena, such as pitting corrosion, three droplets were dropped on each sample and the samples were subjected to five wet-dry cycle tests twice. In total, 30 test cycles were performed. During the test, the temperature was maintained constant at $298 \mathrm{~K}$ and the $\mathrm{RH}$ was decreased from $95 \%$ to $45 \%$ at a constant rate of $5 \% \mathrm{~h}^{-1}$. Subsequently, it was increased from $45 \%$ to $95 \%$ at the same rate. The $E_{\mathrm{SS}-\mathrm{Ag}}$ of these droplets was monitored during the drying and wetting process using a digital multimeter (2000 MULTIMETER, Keithley Instruments, Inc.) and the RH for the pit initiation and repassivation during the drying process $\left(\mathrm{RH}_{\text {pit }}\right)$ and wetting process $\left(\mathrm{RH}_{\text {rep }}\right)$, respectively, was determined. When the air/droplet interface is in equilibrium, the relationship between the equilibrium relative humidity $\left(\mathrm{RH}_{\mathrm{eq}}\right)$ and equilibrium $\mathrm{Cl}^{-}$concentration $\left(\left[\mathrm{Cl}^{-}\right]_{\mathrm{eq}}\right)$ of the droplet can be expressed as follows:

$$
\left[\mathrm{Cl}_{\mathrm{eq}}^{-}\right]=-0.000457 \mathrm{RH}_{\mathrm{eq}}^{2}-0.0705 \mathrm{RH}_{\mathrm{eq}}+12.71 .
$$

The $\left[\mathrm{Cl}^{-}\right]_{\mathrm{eq}}$ for pit initiation $\left(\left[\mathrm{Cl}^{-}\right]_{\mathrm{pit}}\right)$ and repassivation $\left(\left[\mathrm{Cl}^{-}\right]_{\text {rep }}\right)$ was determined by using eq. (3). The number of pits that formed during the wet-dry cycle test and their morphology were observed using a stereoscopic microscope (SMZ800N, Nikon Instech Co., Ltd.) and optical microscope (LV150, Nikon Instech Co., Ltd.), respectively.

\section{Results and Discussion}

\subsection{Automatic pit growth stop test}

Figure 3(a) shows typical changes in the RH and potential $\left(E_{\mathrm{SS}-\mathrm{Ag}}\right)$ for $60 \mathrm{~S}$ steel during the drying process. The $E_{\mathrm{SS}-\mathrm{Ag}}$ gradually increases with the decrease in the $\mathrm{RH}$ from the start of the test up to $8.2 \mathrm{~h}$. However, as reported in a previous study, ${ }^{3)}$ the $\left[\mathrm{Cl}^{-}\right]$in the droplet increases with decreasing $\mathrm{RH}$, which induces the shift of the RE potential in the positive direction. Thus, this potential change does not correspond to the pitting corrosion of $60 \mathrm{~S}$ steel. Subsequently, $E_{\mathrm{SS}-\mathrm{Ag}}$ rapidly shifts in the negative direction at $\sim 8.2 \mathrm{~h}$, which is considered to be due to the occurrence of pitting corrosion.

Figure 3(b) is an enlarged view of Fig. 3(a) at $\sim 8.2 \mathrm{~h}(55 \%$ $\mathrm{RH})$. In this study, the time and $\mathrm{RH}$ at which the change in $E_{\text {SS-Ag }}$ is $-0.01 \mathrm{~V} \mathrm{~s}^{-1}$ were defined as the onset time $\left(t_{\text {onset }}\right)$ and $\mathrm{RH}\left(\mathrm{RH}_{\text {pit }}\right)$ for pit initiation, respectively. In addition, the time when the pit growth automatically stopped (repassivation) by controlling the solenoid valve using the PC and 

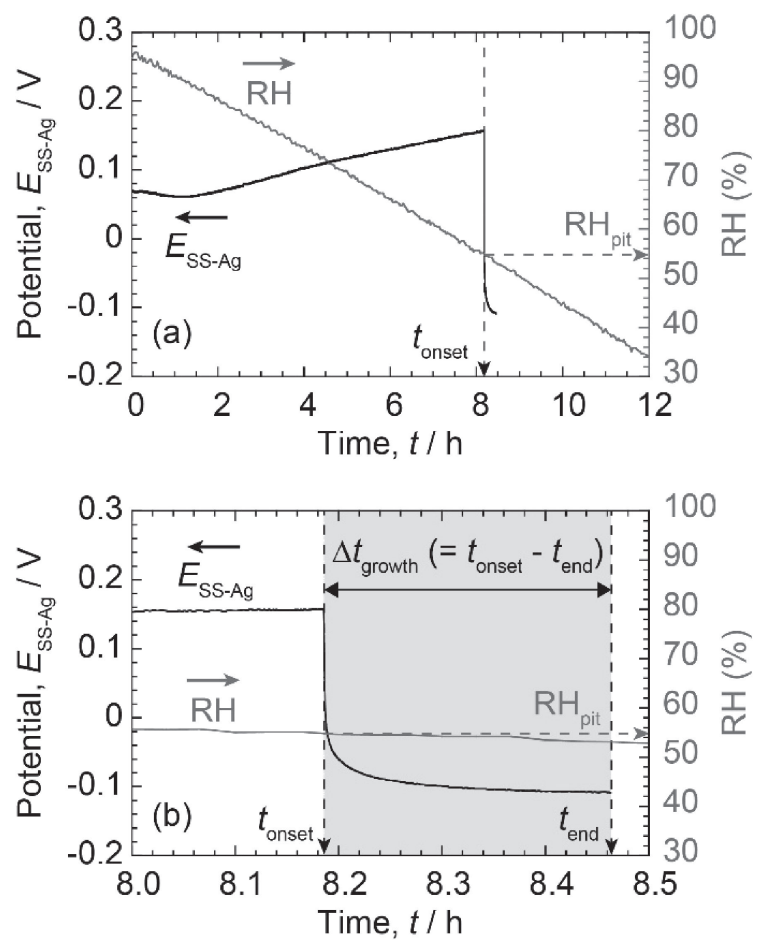

Fig. 3 Typical changes in the RH and $E_{\mathrm{SS}-\mathrm{Ag}}$ of austenitic stainless steel for $60 \mathrm{~S}$ steel (a) from $95 \% \mathrm{RH}$ to $35 \% \mathrm{RH}$, and (b) magnified view of (a) at $\sim 55 \% \mathrm{RH}$

supplying Milli-Q to the sample surface was defined as the end of pit growth $\left(t_{\text {end }}\right)$. A rapid potential change was observed regardless of the S concentration of the SS during the experiments. Hence, the pit growth time $\left(\Delta t_{\text {growth }}=\right.$ $\left.t_{\text {end }}-t_{\text {onset }}\right)$ was liberally controlled and the initiated pits were observed after their growth using SEM.
Figures 4(a)-(d) represent the SEM images of pits that formed on the $60 \mathrm{~S}$ steel surface when $\Delta t_{\text {growth }}$ was 1,10 , 101 , and $1000 \mathrm{~s}$, respectively. These images do not show sequential pit growth for one pit and each pit was separately obtained using different samples. Because the pit growth speeds up significantly, they are shown at different magnifications. Only one pit formed under the droplet during the experiment regardless of $\Delta t_{\text {growth. }}$ In each case, a small deep hole with inclusions can be observed in the center part. In addition, traces of active dissolution around the hole can be observed. The inclusions (point A) in the hole in Fig. 4(a) were analyzed by SEM-EDX (Table 2). The chemical composition ratio of $\mathrm{Mn}$ to $\mathrm{S}$ is approximately $1: 1$, which indicates that these inclusions are $\mathrm{MnS}$ containing chromium and $\mathrm{Fe}$. In addition, because aluminum (Al) and oxygen $(\mathrm{O})$ were also detected, it is highly possible that $\mathrm{MnS}$ inclusions are present near the $\mathrm{Al}_{2} \mathrm{O}_{3}$ inclusions. As described in a previous report, ${ }^{3)}$ the $\mathrm{Ag}$ wire used as $\mathrm{RE}$ partially dissolves as the Ag complex ions in the high $\left[\mathrm{Cl}^{-}\right]$ droplet ( $\sim 10 \mathrm{M}$ in $\mathrm{MgCl}_{2}$ saturation concentration). These ions react with the $\mathrm{MnS}$ inclusions to form $\mathrm{AgS}$ on the $\mathrm{MnS}$ surface. Thus, Ag was also detected by EDX. It is unclear how the precipitation of $\mathrm{Ag}$ affects the pit initiation and growth. However, no suitable RE alternative has been found; therefore, Ag wire was used as RE in this study.

It has been reported that the initiation sites of pits that formed by anodic polarization in the aqueous solution are at the border between the MnS inclusions and SS matrix. ${ }^{12,13)}$ Even in the pit that formed during the drying process of the droplet (non-polarized state), pit initiation most like occurs at the border between the inclusions and matrix because the $\mathrm{MnS}$ inclusions remain in the hole. Furthermore, it can be seen that the active dissolution area radially spreads out from the hole in Fig. 4(a). The diameter of the active dissolution
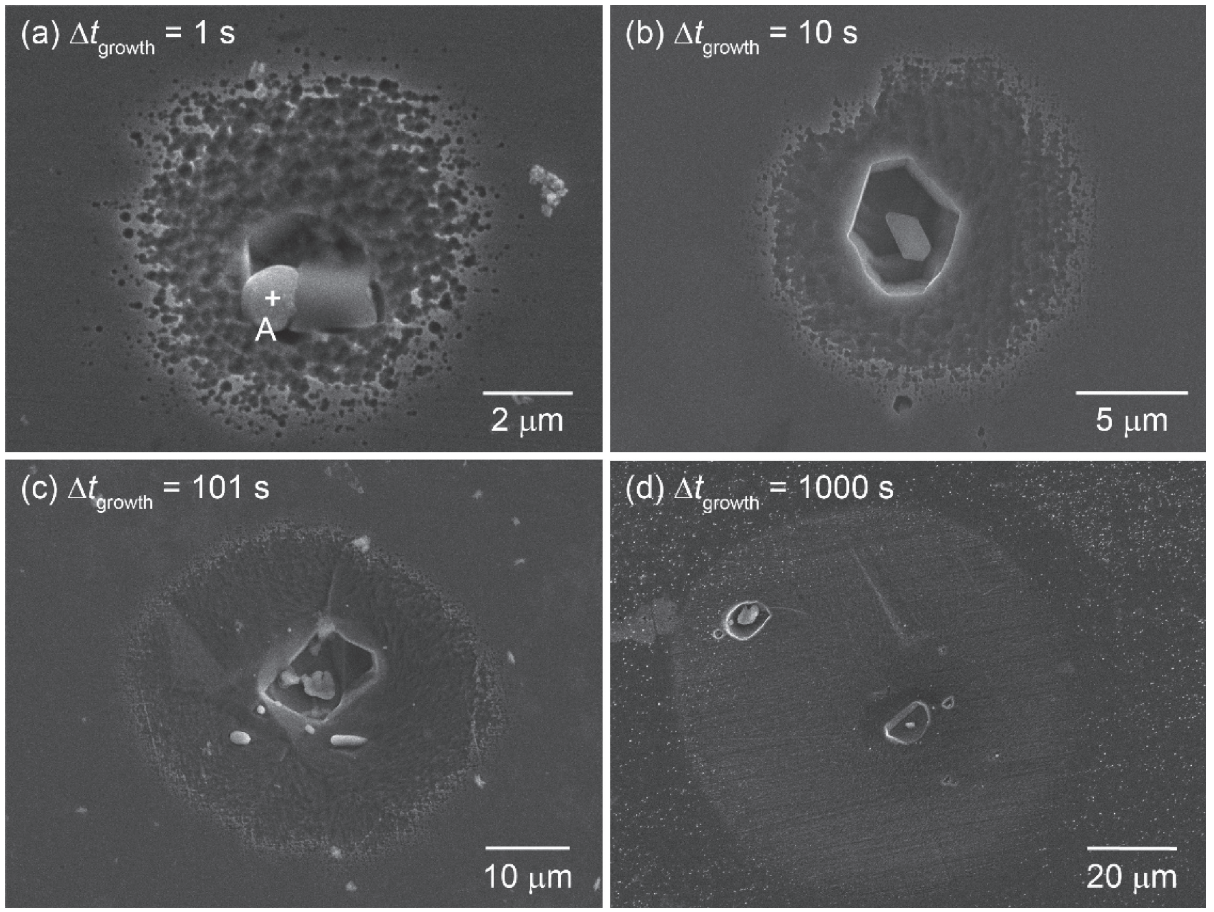

Fig. 4 SEM images of the pit morphology of the $60 \mathrm{~S}$ steel surface with $\Delta t_{\text {growth }}$ of (a) $1 \mathrm{~s}$, (b) $10 \mathrm{~s}$, (c) $101 \mathrm{~s}$, and (d) $1000 \mathrm{~s}$. Point A indicates the EDS point analysis area. 
Table 2 Chemical compositions (at $\%$ ) of inclusions in the pit on the $60 \mathrm{~S}$ steel surface with $\Delta t_{\text {growth }}=1 \mathrm{~s}$.

\begin{tabular}{ccccccccc}
\hline Elements & $\mathrm{S}$ & $\mathrm{Mn}$ & $\mathrm{Cr}$ & $\mathrm{Fe}$ & $\mathrm{Ni}$ & $\mathrm{O}$ & $\mathrm{Al}$ & $\mathrm{Ag}$ \\
\hline Point A & 31.67 & 32.20 & 5.95 & 9.74 & -- & 11.23 & 6.31 & 2.90 \\
\hline
\end{tabular}

area $\left(d_{\text {active }}\right)$ at $\Delta t_{\text {growth }}=1 \mathrm{~s}$ was determined to be roughly $7.5 \mu \mathrm{m}$. Assuming that the entire surface of the droplet acts as a cathode site, the corroded area $\left(V_{\text {corr }}\right)$ can be expressed by the following equation:

$$
V_{\text {corr }}=\frac{\pi\left(\frac{d_{\text {drop }}}{2}\right)^{2} \times i_{\text {cath }} \times \Delta t_{\text {growth }}}{2 \mathrm{~F}} \times \frac{\mathrm{M}_{\mathrm{Fe}}}{d_{\mathrm{Fe}}}
$$

where $d_{\text {drop }}, \mathrm{F}, \mathrm{M}_{\mathrm{Fe}}$, and $d_{\mathrm{Fe}}$ represent the diameter of the droplet $(0.3 \mathrm{~cm})$, Faraday constant $\left(96485 \mathrm{C} \mathrm{mol}^{-1}\right)$, molecular weight of $\mathrm{Fe}\left(55.845 \mathrm{~g} \mathrm{~mol}^{-1}\right)$, and density of $\mathrm{Fe}$ $\left(7.874 \mathrm{~g} \mathrm{~cm}^{-3}\right)$, respectively. Assuming that $i_{\text {cath }}$, which is the oxygen diffusion-limiting current, is $2.0 \times 10^{-5} \mathrm{~A} \mathrm{~cm}^{-2}$, $V_{\text {corr }}$ is $5.2 \times 10^{-11} \mathrm{~cm}^{3}$ when $\Delta t_{\text {growth }}$ is equal to $1 \mathrm{~s}$. As shown in Fig. 4(a), the actual active dissolution area is considerably irregular. Based on the assumption that the shape of the dissolution area is a hemisphere, the active dissolution area can be calculated to be $5.8 \mu \mathrm{m}$ by substituting the value of $V_{\text {corr }}$. Because the calculated value is much closer to $d_{\text {active }}$, it is highly possible that the pit grows to $7.5 \mu \mathrm{m}$ within only $1 \mathrm{~s}$.

As $\Delta t_{\text {growth }}$ increases from $1 \mathrm{~s}$ to $10 \mathrm{~s}, 101 \mathrm{~s}$, and $1000 \mathrm{~s}$, $d_{\text {active }}$ increases to 14,31 , and $90 \mu \mathrm{m}$, respectively. Figure 5 shows the relationship between $d_{\text {active }}$ and $\Delta t_{\text {growth, which can }}$ be expressed as follows:

$$
d_{\text {active }}=6.7 \Delta t_{\text {growth }}^{0.36} .
$$

In other words, the increase in the active dissolution area of pitting corrosion is proportional to $\sim 1 / 3$ power of the time. When $\Delta t_{\text {growth }}$ changes from 1 to $1000 \mathrm{~s}$, the diameter

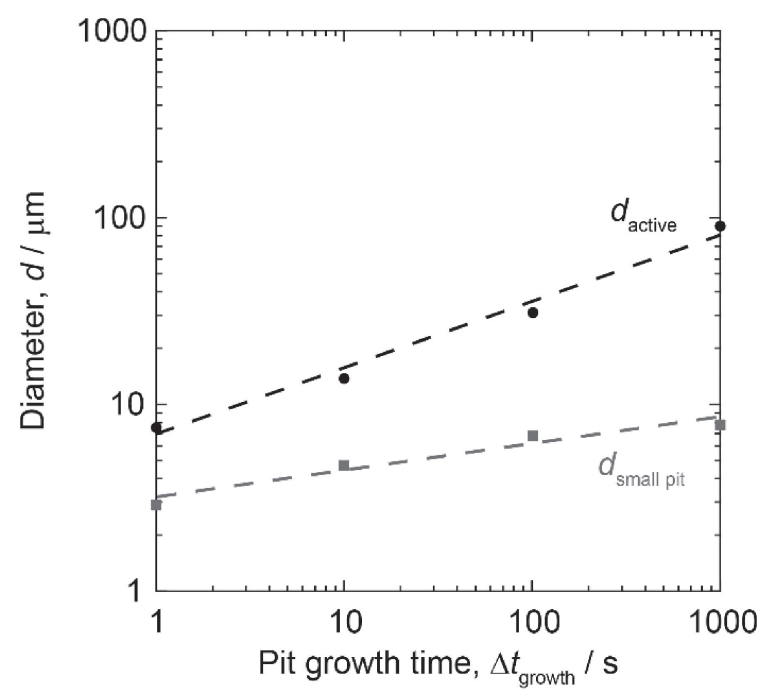

Fig. 5 Diameters of the active surface area $\left(d_{\text {active }}\right)$ and deep small pit $\left(d_{\text {small pit }}\right)$ as a function of the pit growth time $\left(\Delta t_{\text {growth }}\right)$. $\left(d_{\text {small pit }}\right)$ and depth of the small deep hole in the central part ranges from 2.9 to $7.8 \mu \mathrm{m}$ and 2.5 to $5.0 \mu \mathrm{m}$, respectively. The growth of these areas is smaller compared with that of the active dissolution area. Therefore, the initial anodic site should be the small hole immediately after pit initiation. The anodic site then radially spreads from the hole to the outside (active dissolution area) because the $\mathrm{pH}$ of the surrounding area of the hole decreases based on the hydrolysis reaction of metal ions dissolved in the hole; as a result, the growth of the small hole (initiation site) stops.

Figure 6 depicts SEM images of the pits that formed on the steel surfaces depending on the $\mathrm{S}$ concentration at a $\Delta t_{\text {growth }}$ value of $\sim 10 \mathrm{~s}$. Note that only one pit is initiated on the surface in the droplet regardless of the $\mathrm{S}$ concentration. A small deep hole in the center of the pit can be observed, similar to the 60S steel (Fig. 4(b)) and the active dissolution area radially spreads around the hole. The MnS inclusions remain inside the holes, except for $10 \mathrm{~S}$ steel. On the other hand, no inclusions can be identified in the hole of the $10 \mathrm{~S}$ steel because the inclusions of the 10S steel are extremely small (Fig. 1(a)) and detach from the hole. The diameter of the active dissolution area ranges from 12 to $24 \mu \mathrm{m}$ in all samples and the $\mathrm{S}$ concentration does not affect the radial pit growth. In brief, the initiation sites of pitting corrosion are $\mathrm{MnS}$ inclusions, even if the $\mathrm{S}$ concentration differs. The number and size of the inclusions have almost no effect on the growth rate of the pits during the early stage of pit growth within $\sim 10$ s.

\subsection{Wet-dry cycle test}

Figures 7(a) and (b) show the representative change in $\mathrm{RH}$ and $\left[\mathrm{Cl}^{-}\right]$in the droplet calculated by using eq. (3) and $E_{\mathrm{SS}-\mathrm{Ag}}$ of $60 \mathrm{~S}$ steel during wet-dry cycle test, respectively. From the start of the test until $7.3 \mathrm{~h}, E_{\mathrm{SS}-\mathrm{Ag}}$ gradually increases with decreasing RH. This potential shift is considered to be due to the $\mathrm{Cl}^{-}$condensation, as described in Section 3.1. Subsequently, $E_{\mathrm{SS}-\mathrm{Ag}}$ suddenly shifts into the negative direction due to the pit initiation. The onset time of pit initiation $\left(t_{\text {onset }}\right)$ is the same as that defined in Section 3.1 and the $\mathrm{RH}$ and $\left[\mathrm{Cl}^{-}\right]$during pit initiation are defined as $\mathrm{RH}_{\text {pit }}$ and $\left[\mathrm{Cl}^{-}\right]_{\text {pit }}$, respectively. The $E_{\mathrm{SS}-\mathrm{Ag}}$ value becomes constant (approximately $-0.1 \mathrm{~V}$ ) under the active dissolution potential for $\sim 8 \mathrm{~h}$ and then moves into the noble direction due to the repassivation of the pit during the wetting process. The repassivation time of the initiated pit is defined as $t_{\text {rep }}$ when $E_{\text {SS-Ag }}$ reaches $0 \mathrm{~V}$ during the transition of the potential toward the noble direction and the $\mathrm{RH}$ and $\left[\mathrm{Cl}^{-}\right]$during the repassivation are defined as $\mathrm{RH}_{\text {rep }}$ and $\left[\mathrm{Cl}^{-}\right]_{\text {rep }}$, respectively.

Figure 8 exhibits one of the examples of changes in $E_{\mathrm{SS}-\mathrm{Ag}}$ and RH when (a) 60S steel and (b) 3230S steel are subjected to five wet-dry cycle tests. The highlighted area in the figures 

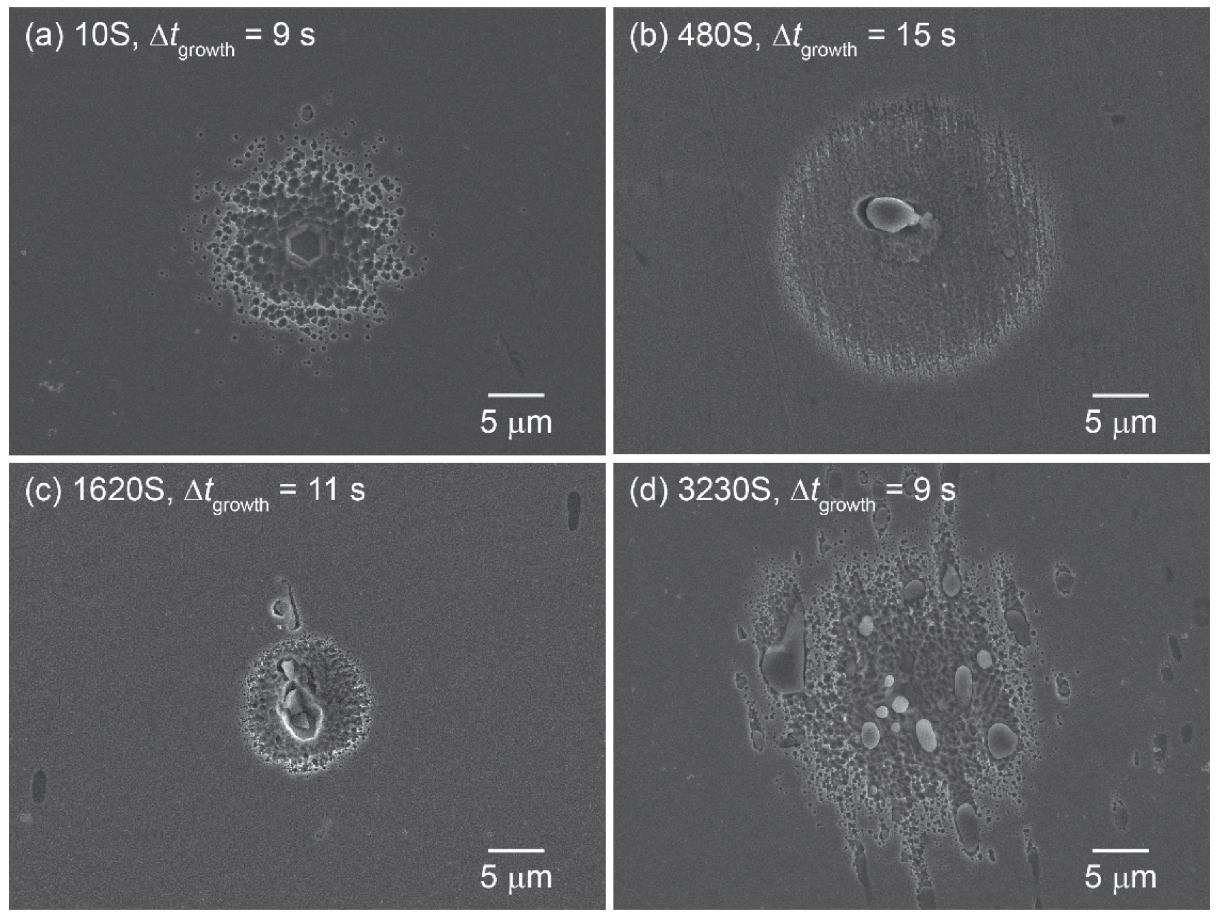

Fig. 6 SEM images of the pit morphology of the (a) $10 \mathrm{~S}$, (b) $480 \mathrm{~S}$, (c) $1620 \mathrm{~S}$, and (d) $3230 \mathrm{~S}$ steel surface at $\Delta t_{\text {growth }}$ of $\sim 10 \mathrm{~s}$.

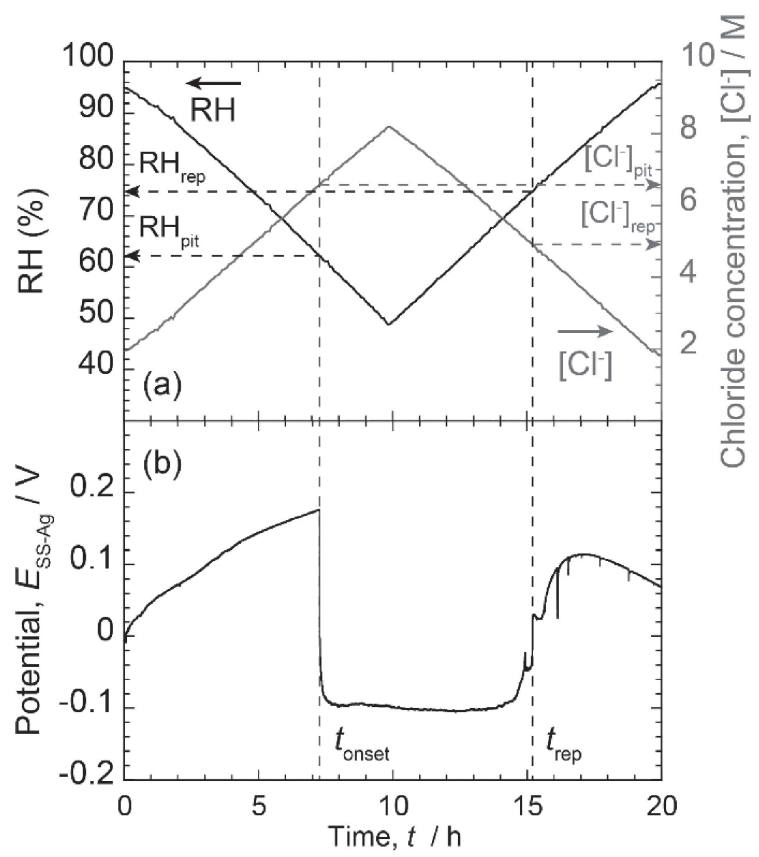

Fig. 7 Typical change in the $E_{\mathrm{SS}-\mathrm{Ag}}$ of $60 \mathrm{~S}$ steel during the $\mathrm{RH}$ cycle, (a) RH change and chloride concentration $\left[\mathrm{Cl}^{-}\right]$calculated from the $\mathrm{RH}$ change using eq. (3) and (b) potential change of $E_{\mathrm{SS}-\mathrm{Ag}}$ of $60 \mathrm{~S}$ steel. Definitions of $\mathrm{RH}_{\text {pit }}$ at the onset of pitting corrosion (point " $t_{\text {onset }}$ ") and $\mathrm{RH}_{\text {rep }}$ at the onset of repassivation (point " $t_{\text {rep }}$ ").

corresponds to the pit growth time. The pit growth time increases with increasing S concentration of the SS. Figure 9 shows optical microscope images of pits that formed on the (a) $60 \mathrm{~S}$ and (b) $3230 \mathrm{~S}$ steel surfaces during the five wet-dry cycle tests. In addition, Figs. 9(c)-(e) are magnified images of the pit (Fig. 9(b)) that formed on the 3230S steel surface. First, as shown for 60S steel (Fig. 8(a)), the potential shifts in both the negative and positive directions occur in each cycle
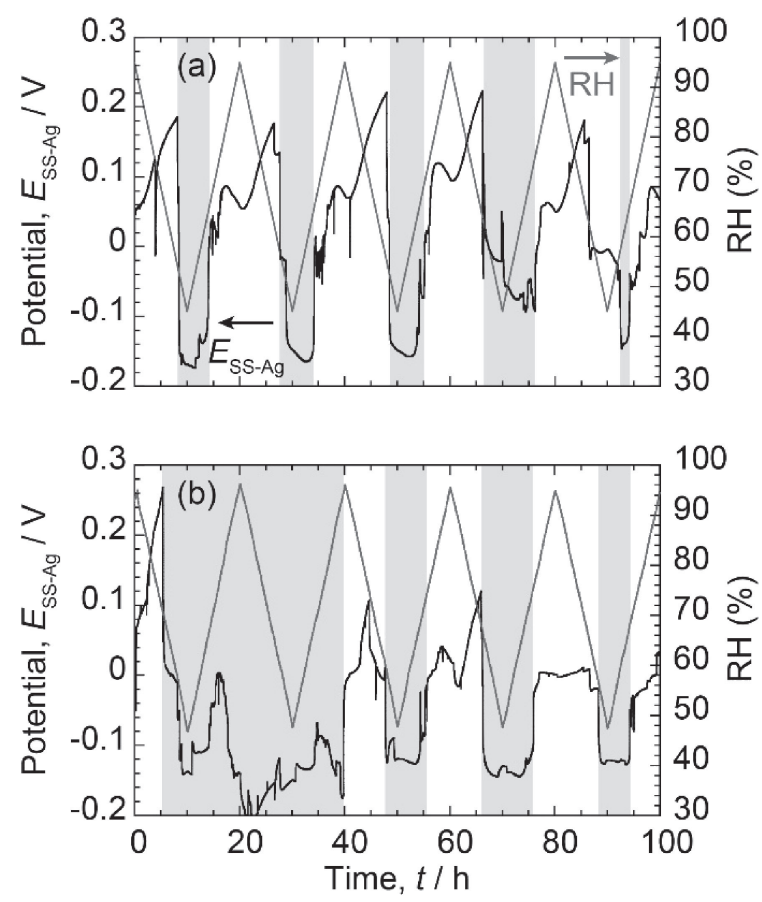

Fig. 8 Changes in $E_{\mathrm{SS}-\mathrm{Ag}}$ for (a) $60 \mathrm{~S}$ and (b) $3230 \mathrm{~S}$ steel exposed to five $\mathrm{RH}$ cycles between $95 \%$ and $45 \%$. The highlighted area indicates the growth period of pitting corrosion $\left(\Delta t_{\text {growth }}\right)$.

of the wet-dry cycle tests. Because the number of potential fluctuations is consistent with the number of initiated pits observed on the 60S steel surface (Fig. 9(a)), a sharp decrease and increase in the potential results in the initiation and repassivation of a pit, respectively. The results of the wet-dry cycle test show that five pits form on the $60 \mathrm{~S}$ steel surface during five cycles. However, because pitting corrosion is a stochastic phenomenon, the probability of pitting corrosion $\left(\mathrm{P}_{\text {pit }}\right)$ will be discussed later. Second, the 

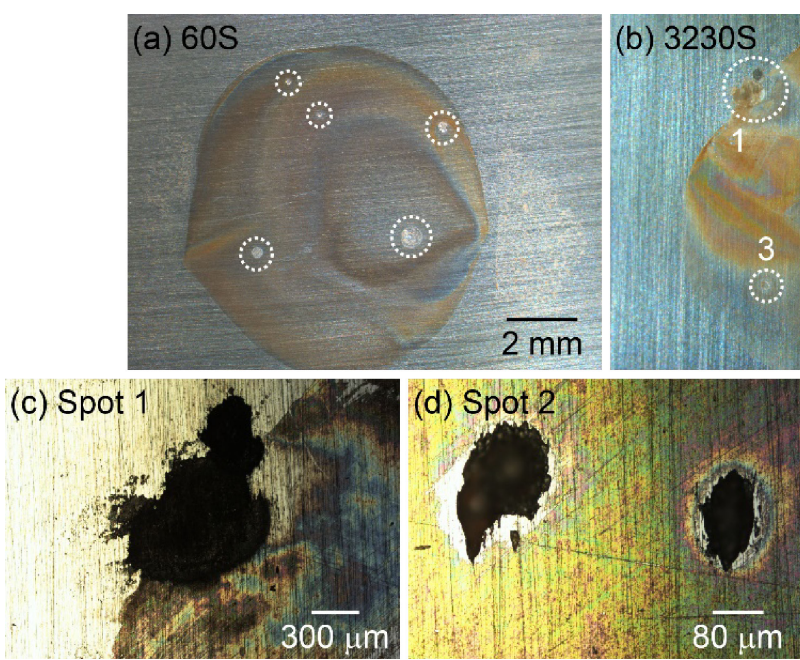

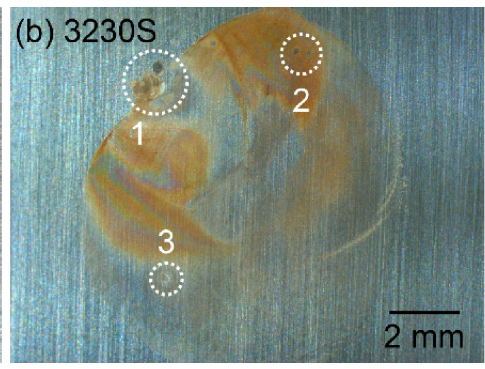

(e) Spot 3

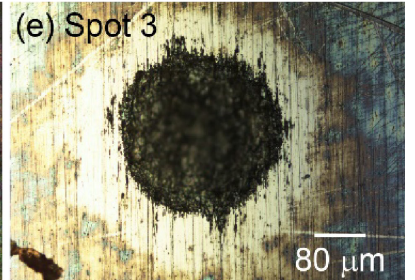

Fig. 9 Optical microscope images of pits on (a) 60S, and (b) $3230 \mathrm{~S}$ steel after exposure to five RH cycles. The dotted white circles indicate the pit positions. The magnified pit morphologies observed on $3230 \mathrm{~S}$ steel are shown in (c), (d), and (e), respectively.

potential fluctuation can also be observed for $3230 \mathrm{~S}$ steel. However, in the first cycle, although a negative shift of the potential to the initiation of the pit can be observed in the drying process, the positive potential shift due to pit repassivation does not occur in the wetting process and $E_{\mathrm{SS}-\mathrm{Ag}}$ remains below $0 \mathrm{~V}$. Even in the initial stage of the drying process in the second cycle (high $\mathrm{RH}$ region), $E_{\mathrm{SS}-\mathrm{Ag}}$ remains below $0 \mathrm{~V}$ without repassivation; a potential shift due to repassivation can be observed at the end of the wetting process. After the test, four pits were observed on the $3230 \mathrm{~S}$ steel surface (Fig. 9(b)), which corresponds to the number of potential fluctuations monitored by the Ag wire shown in Fig. 8(b). However, one of the four pits (Fig. 9(c)) grows significantly more than the others. In other words, it is highly possible that the initiated pit did not repassivate in the wetting process during the first cycle and continued to grow in the second cycle, resulting in large pit formation. This phenomenon is only noticeable when the S concentrations of SS is high.

To evaluate the effect of the S concentration of SS on the pit initiation, $\mathrm{P}_{\text {pit }}$ was calculated by using eq. (6) and all results of the wet-dry cycle tests:

$$
\mathrm{P}_{\mathrm{pit}}=\frac{\mathrm{N}_{\mathrm{pit}}}{\mathrm{N}_{\text {total }}}
$$

where $\mathrm{N}_{\text {pit }}$ and $\mathrm{N}_{\text {total }}$ indicate the number of initiated pits and wet-dry cycles, respectively. However, the number of cycles is regarded to be one when the pit growth straddled two cycles, as shown in Fig. 8(b). The number of repassivated pits in the wetting process was defined as $\mathrm{N}_{\text {rep }}$, and the pit repassivation probability $\left(\mathrm{P}_{\text {rep }}\right)$ was calculated as follows:

$$
\mathrm{P}_{\text {rep }}=\frac{\mathrm{N}_{\text {rep }}}{\mathrm{N}_{\text {pit }}} \text {. }
$$

Figure 10(a) shows the correlations between the $\mathrm{S}$ concentration of SS and $\mathrm{P}_{\text {pit }}$ and $\mathrm{P}_{\text {rep. The }} \mathrm{P}_{\text {pit }}$ value is $\sim 60 \%$ when the $\mathrm{S}$ concentration of SS is $10 \mathrm{ppm}$ and increases sharply with increasing S concentration. Finally, $\mathrm{P}_{\text {pit }}$ reaches $100 \%$ when the $\mathrm{S}$ concentration is above $1000 \mathrm{ppm}$. This means that pits were initiated in all cycles of the wet-dry cycle tests.

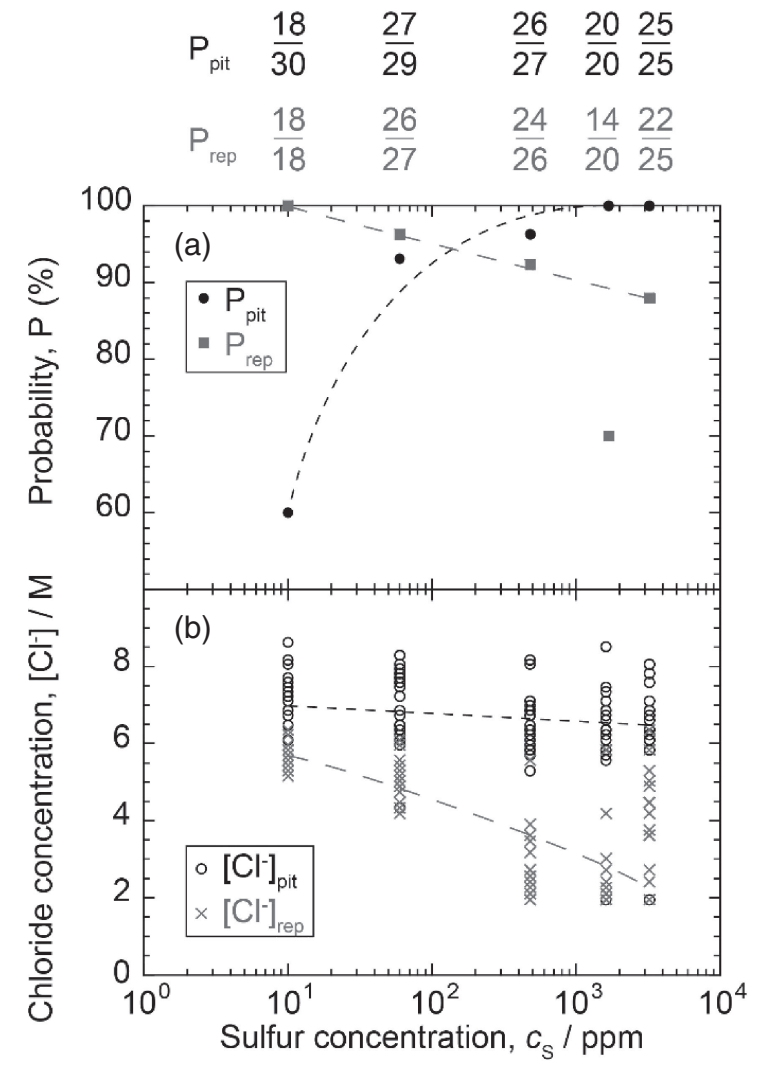

Fig. 10 (a) $\mathrm{P}_{\text {pit }}$ and $\mathrm{P}_{\text {rep }}$ as well as (b) $\left[\mathrm{Cl}^{-}\right]_{\text {pit }}$ and $\left[\mathrm{Cl}^{-}\right]_{\text {rep }}$ vs. the sulfur concentration of austenitic stainless steel.

Furthermore, $\mathrm{P}_{\text {rep }}$ decreases with increasing $\mathrm{S}$ concentration of SS and the initiated pit is less likely to be repassivated.

By substituting the measured $\mathrm{RH}_{\text {pit }}$ and $\mathrm{RH}_{\text {rep }}$ values into eq. (3), $\left[\mathrm{Cl}^{-}\right]_{\text {pit }}$ and $\left[\mathrm{Cl}^{-}\right]_{\text {rep }}$ during pit initiation and repassivation, respectively, were calculated. The results were plotted against the S concentration, as shown in Fig. 10(b). Due to the stochastic nature of pitting corrosion, $\left[\mathrm{Cl}^{-}\right]_{\text {pit }}$ varies, to some extent, even in the same sample; however, it mostly ranges from 5.5 to $8.5 \mathrm{M}$ and a dependency on the $\mathrm{S}$ concentration cannot be observed. Therefore, as the number 
of $\mathrm{MnS}$ inclusions increases with increasing $\mathrm{S}$ concentration, the probability of $\mathrm{MnS}$ inclusions, which are the initiation sites of pitting corrosion, in the droplet also increases, which enhances the probability of pitting corrosion. On the other hand, $\left[\mathrm{Cl}^{-}\right]_{\text {rep }}$ decreases with increasing $\mathrm{S}$ concentration, which implies that repassivation is less likely to occur with increasing $\mathrm{S}$ concentration. Due to the expansion of the active dissolution area (Fig. 6), the amount of MnS inclusions increases in this area with increasing $\mathrm{S}$ concentration. Because the initial volume of the droplet is constant regardless of the $\mathrm{S}$ concentration, the number of $\mathrm{MnS}$ inclusions in the active dissolution area might change the environment in the droplet and thus may affect the repassivation behavior. Webb et al. ${ }^{22)}$ observed the evolution of $\mathrm{HS}^{-}$from $\mathrm{MnS}$ inclusions on a SS surface immersed in $0.1 \mathrm{M} \mathrm{Na}_{2} \mathrm{SO}_{4}(\mathrm{pH}=2)$ and proposed that $\mathrm{MnS}$ chemically dissolves in low-pH solution based on the following equation:

$$
\mathrm{MnS}+\mathrm{H}^{+} \rightarrow \mathrm{Mn}^{2+}+\mathrm{HS}^{-} .
$$

Because the $\mathrm{pH}$ of the active dissolution area decreases due to the hydrolysis reaction of the dissolved metal ions, the $\mathrm{MnS}$ inclusions in the active dissolution area chemically dissolve and $\mathrm{HS}^{-}$forms due to the expansion of the area. Because the acid dissociation constant $\left(\mathrm{pK}_{\mathrm{a}}\right)$ of $\mathrm{HS}^{-}$is $7.02^{23}$ ) the ratio of $\mathrm{H}_{2} \mathrm{~S}$ and $\mathrm{HS}^{-}$can be expressed by the following equation:

$$
\frac{\left[\mathrm{H}_{2} \mathrm{~S}\right]}{\left[\mathrm{HS}^{-}\right]}=10^{7.02}\left[\mathrm{H}^{+}\right] \text {. }
$$

In other words, $\mathrm{HS}^{-}$that forms by chemical dissolution almost changes to $\mathrm{H}_{2} \mathrm{~S}$ in a low-pH environment. Based on previous reports, ${ }^{24-26)} \mathrm{H}_{2} \mathrm{~S}$ promotes the destruction of the passive film on the SS surface and shift of the pitting potential to the negative direction, suggesting that $\mathrm{H}_{2} \mathrm{~S}$ that forms by the chemical dissolution of $\mathrm{MnS}$ inclusions might inhibit the repassivation of SS. In the future, a more detailed study of the effect of the $\mathrm{S}$ concentration on the repassivation behavior will be performed.

\section{Conclusions}

The corrosion behavior of austenitic SS with different S concentrations was investigated using automatic pit growth stop and wet-dry cycle tests. The findings are as follows:

(1) We established an electrochemical measurement system based on which the pit growth automatically stops and pits with a growth time of 1 to $1000 \mathrm{~s}$ (after initiation) can be observed using SEM. The system was applied to $\mathrm{SS}$ with different $\mathrm{S}$ concentrations. The results confirm that the initiation sites of pitting corrosion are $\mathrm{MnS}$ inclusions and that the growth behavior of the active dissolution area does not change regardless of the $\mathrm{S}$ concentration.
(2) As the $\mathrm{S}$ concentration increases, the probability of $\mathrm{MnS}$ inclusions in the droplet and thus the probability of pitting corrosion increase. In addition, the chloride ion concentration does not differ when pits are initiated because the initiation sites of pitting corrosion are $\mathrm{MnS}$ inclusions regardless of the $\mathrm{S}$ concentration in SS. On the other hand, the repassivation of the initiated pits strongly depends on the $\mathrm{S}$ concentration and becomes difficult when the $\mathrm{S}$ concentration increases.

\section{REFERENCES}

1) Y. Tsutsumi, A. Nishikata and T. Tsuru: J. Electrochem. Soc. 152 (2005) B358-B363.

2) S. Hastuty, Y. Tsutsumi, A. Nishikata and T. Tsuru: ISIJ Int. 52 (2012) 863-867.

3) T. Van Nam, E. Tada and A. Nishikata: J. Electrochem. Soc. 162 (2015) C419-C425.

4) T. Van Nam, E. Tada and A. Nishikata: Mater. Trans. 56 (2015) 12191225.

5) G.S. Frankel: J. Electrochem. Soc. 145 (1998) 2186-2198.

6) H. Böhni, T. Suter and A. Schreyer: Electrochim. Acta 40 (1995) 13611368.

7) T. Suter and H. Böhni: Electrochim. Acta 42 (1997) 3275-3280.

8) T. Suter, E.G. Webb, H. Böhni and R.C. Alkire: J. Electrochem. Soc. 148 (2001) B174-B185.

9) E.G. Webb, T. Suter and R.C. Alkire: J. Electrochem. Soc. 148 (2001) B186-B195.

10) E.G. Webb and R.C. Alkire: J. Electrochem. Soc. 149 (2002) B272B279.

11) E.G. Webb and R.C. Alkire: J. Electrochem. Soc. 149 (2002) B280B285.

12) A. Chiba, I. Muto, Y. Sugawara and N. Hara: J. Electrochem. Soc. 159 (2012) C341-C350.

13) A. Chiba, I. Muto, Y. Sugawara and N. Hara: J. Electrochem. Soc. 160 (2013) C511-C520.

14) A. Chiba, I. Muto, Y. Sugawara and N. Hara: Mater. Trans. 55 (2014) 857-860.

15) M. Stratmann and H. Streckel: Corros. Sci. 30 (1990) 681-696.

16) M. Stratmann and H. Streckel: Corros. Sci. 30 (1990) 697-714.

17) M. Stratmann, H. Streckel, K.T. Kim and S. Crockett: Corros. Sci. 30 (1990) 715-734.

18) G.S. Frankel, M. Stratmann, M. Rohwerder, A. Michalik, B. Maier, J. Dora and M. Wicinski: Corros. Sci. 49 (2007) 2021-2036.

19) Y. Shi, E. Tada and A. Nishikata: J. Electrochem. Soc. 162 (2015) C135-C139.

20) C. Somphotch, H. Hayashibara, A. Ooi, E. Tada and A. Nishikata: J. Electrochem. Soc. 165 (2018) C590-C600.

21) Y. Tsutsumi, A. Nishikata and T. Tsuru: J. Electrochem. Soc. 153 (2006) B278-B282.

22) E.G. Webb, C.H. Paik and R.C. Alkire: Electrochem. Solid-State Lett. 4 (2001) B15-B18.

23) W. Sun, S. Nešić and D. Young: Ind. Eng. Chem. Res. 47 (2008) 17381742 .

24) C.S. Brossia and R.G. Kelly: Corros. Sci. 40 (1998) 1851-1871.

25) L. Zhang, X. Tang, Z. Wang, T. Li, Z. Zhang and M. Lu: Int. J. Electrochem. Sci. 12 (2017) 8806-8819.

26) M.M.A.M. Schvartzman, D.R. Lopes, L. Esteves, W.R.C. Campos and V.F.C. Lins: J. Mater. Eng. Perform. 27 (2018) 3723-3730. 